\title{
Struktur dan Fungsi Cerita Petilasan Ki Semar di Gunung Srandil Desa Glempang Pasir Kecamatan Adipala Kabupaten Cilacap Tahun 2017
}

\author{
Febri Ahmad Lutfi ${ }^{\bowtie}$, Mulyono, U’um Qomariyah \\ Jurusan Bahasa dan Sastra Indonesia, Fakultas Bahasa dan Seni, Universitas Negeri Semarang, \\ Indonesia
}

\begin{tabular}{l}
\hline Info Artikel \\
\hline Sejarah Artikel: \\
Diterima Mei 2017 \\
Disetujui Agustus 2017 \\
Dipublikasikan Maret \\
2018 \\
\hline Keywords: \\
oral literature; Levi \\
Strauss's structuralism \\
theory \\
\hline
\end{tabular}

\begin{abstract}
Abstrak
Tujuan penelitian ini adalah mengetahui struktur, makna, dan fungsi mitos cerita petilasan $K i$ Semar di Gunng Srandil di Desa Glempang Pasir Kecamatan Adipala Kabupaten Cilacap. Pendekatan penelitian ini adalah pendekatan deskriptif kualitatif. Data penelitian ini adalah cerita petilasan Ki Semar, sedangkan sumber data penelitian ini adalah tuturan versi cerita dari masingmasing informan. Pengumpulan data menggunakan teknik wawancara, pengamatan secara langsung, dan teknik dokumentasi. Hasil penelitian ini menunjukan bahwa struktur cerita petilasan Ki Kemar di Gunung Srandil terdiri dari empat versi cerita. Versi cerita dari Buku Gunung Srandil dan Selok karya Sidik Purnama Negara terdiri dari 23 untit naratif yang digolongkan menjadi 3 episode, Versi cerita dari Warga Pendatang terdiri dari 9 unit naratif yang digolongkan menjadi 4 episode, Versi Cerita menurut Juru Kunci digolongkan menjadi 8 unit naratif yang digolongkan menjadi 3 episode, dan cerita versi warga sekitar digolongkan menjadi 9 unit naratif yang digolongkan menjadi 3 episode. Fungsi cerita petilasan Ki Semar diteliti menggunakan teori fungsi Van Peursen dan menghasilkan fungsi yang terdiri dari (1) Cerita Petilasan Ki Semar mempunyai kekuatan-kekuatan ajaib, dibuktikan dengan dipatuhinya larangan yang diberikan oleh $\mathrm{Ki}$ Semar, (2) dapat memberikan jaminan hidup pada masa kini, dibuktikan dengan banyaknya masyarakat dalam melakukan laku spiritual yang dilakukan oleh Ki Semar. Makna cerita Petilasan Ki Semar di Gunung Srandil diteliti menggunakan teori Hermeneutik Hans-Georg Gadamer. Hasil analisis Hermeneutik Hans-Georg Gadamer pada mitos cerita Petilasan Ki Semar di Gunung Srandil mempunyai makna simbol yang ditafsirkan dalam cerita petilasan Ki Semar (1) Makna dari simbol Gunung pada masyarakat jawa yaitu tempat suci, (2) Makna Sensus Communis dalam penerapan cerita ini yaitu terdapat konsep pemikiran masyarakat tentang kehancuran majapahit yang terkenal dengan penyerbuan kerajaan Majapahit yang dilakukan oleh kerajaan Demak Bintara, padahal apabila dibandingkan dengan pendapat narasumber cerita rakyat ini, bahwa kehancuran Kerajaan Majapahit karena adanya perbedaan faham yang dianut oleh Raden Patah dan Prabu Brawijaya V sehingga membuat aturan sosial berubah di Majapahit dan mengakibatkan perang saudara, (3) Taste atau Selera, cerita petilasan Ki Semar menurut warga sekitar dan pendatang mengatakan bahwa Sabda Palon (Ki Semar) merupakan penasehat Prabu Brawijaya V sedangkan cerita petilasan Ki Semar menurut ceita juru kunci, bahwa Semar merupakan anak dari Sang Hyang Tunggal yang diutus untuk mengasuh para kesatria berbudi luhur.
\end{abstract}

\begin{abstract}
The purpose of this project is to observe the structure, meaning, and function of the myth about Ki Semar's Sanctuary in Srandil Mountain located at Glempang Pasir village, Adipala, Cilacap. This project used kualitative descriptive methods. The data of this project is indeed the Ki Semar's sanctuary, while the source of the data are the various stories about the myth told by the villagers. The data were collected by interviewing and documenting the sources. According to the data collected, there are four versions of story about Ki Semar's Sanctuary. Basically, the story was built in the name of Sabda Palon as Semar and Prabu Brawijaya V. It was classified into some narative units and then into some episodes to analyze between the ceriteme and the
\end{abstract}


Febri Ahmad Lutfi dkk. / Jurnal Sastra Indonesia 7 (1) (2018)

opotitions by using Levi-Strauss' Structuralism Theory. The first version, A book entitled 'Gunung srandil dan Selok' written by Sidik Purnama, included with 3 units of narative was classified into 3 episodes. The second version told by people included 9 units narative which were classified into 4 episodes. There are also 8 units narative told by the 'Juru Kunci' of the sanctuary which were classified into 4 episodes. At last, the story told by the villagers around the sanctuary which were classified into 9 units narative and 3 episodes. The function of the story itself were examined by using Van Pursen's theory and concluding that (1) the story has its own magic proven by how the villagers obeying the forbidden given by Ki Semar as the main character of the story, and (2) it gives a life guarantee to the people who believe in the Ki Semar's priciple in spiritual. Besides the function, the writer also did Hermenuetik analysis by Hans-Georg gadmer to the story and found that (1) the meaning of a mountain symbol for Javanese is a sanctuary, (2) the meaning of Sensus Comunis in the application of the story has a close relation with the falling of Majapahit by Demak Bintara palace, yet the falling of Majapahit was actually because of the different principles between Raden Patah and Prabu Brawijaya V which later became the cause of Majapahit Civil War, (3) The meaning of taste in this story can be concluded that there are two impersonation of Ki Semar, they are as Sabda Palon (according to the villagers), and as the child of Sang Hyang Tunggal who were told to take care of the soldiers (according to the Juru Kunci).

\title{
(C) 2018 Universitas Negeri Semarang
}

\author{
Alamat korespondensi: \\ Gedung B1 Lantai 1 FBS Unnes \\ Kampus Sekaran, Gunungpati, Semarang, 50229 \\ E-mail: febri.lutfi@gmail.com
}

ISSN 2252-6315 


\section{PENDAHULUAN}

Dalam kehidupan modern seperti sekarang masih banyak dijumpai cerita rakyat yang masih hidup dan berkembang di masyarakat. Cerita rakyat tersebut masih banyak dijumpai dalam komunitas masyarakat yang tinggal di daerah tertentu. Banyaknya masyarakat yang memercayai cerita rakyat, maka tidak menutup kemungkinan terjadi perbedaan pandangan dan kepercayaan terhadap cerita rakyat yang mereka yakini. Perbedaan pandangan itulah yang mungkin terletak pada jalannya cerita serta kekuatan mistik yang ada didalam cerita rakyat tersebut.

Seperti halnya cerita petilasan Ki Semar di Gunung Srandil, yang masih berkembang dan hidup di Kabupaten Cilacap. Cerita petilasan $\mathrm{Ki}$ Semar merupakan cerita lisan yang proses penyebarannya menggunakan bahasa secara lisan. Dillihat dari proses penyebarannya secara lisan maka tidak menutup kemungkinan adanya perbedaan pada setiap struktur versi cerita.

Penulis menggolongkan cerita petilasan Ki Semar menjadi empat versi, yaitu menurut juru kunci Gunung Srandil, warga sekitar, warga pendatang, serta buku Gunung Srandil dan selok karya sidik purnama negara. Dari keempat versi cerita tersebut, maka tidak menutup kemungkinan mempunyai dimensi positif dan negatif. Sampai saat ini cerita petilasan Ki Semar pada umumnya mendapat presepsi ke arah dimensi negatif. Dimensi negatif atau pandangan negatif dari cerita petilasan Ki Semar yaitu apabila ingin terkabul akan sesuatu yang dicita-citakan, maka orang yang berziarah atau ngalab berkah harus menyiapkan sesaji tertentu. Pandangan negatif inilah yang masih dianut oleh sebagian masyarakat.

Di samping pandangan negatif ada juga pandangan positif terkait cerita petilasan $K i$ Semar, yaitu sebagai tempat meditasi. Dengan harapan apabila seseorang bermeditasi di tempat tersebut dapat mengambil hikmah dan keutamaan dari perilaku tokoh yang diziarahi. Dengan demikian, dikemudian hari nanti dalam mencapai cita-cita, jika menghadapi halangan maupun rintangan, baik fisik maupun ghaib akan mempunyai ketabahan dan keluhuran jiwa seperti yang diziarahi. Berbagai perbedaan pandangan tersebut mengakibatkan terjadinya pro dan kontra di dalam mitos cerita petilasan Ki Semar, serta berbagai versi cerita yang tumbuh dan berkembang, sehingga mitos cerita petilasan $\mathrm{Ki}$ Semar masih dimitoskan sampai sekarang, dan memunculkan tradisi-tradisi serta tingkah laku yang mencerminkan mitos tersebut, yang sampai saat ini masih dipercaya oleh masyarakat.

Berangkat dari hal tersebut, tujuan yang hendak dicapai dalam penelitian ini adalah menggambarkan struktur, makna dan fungsi mitos cerita Petilasan Ki Semar di Gunung Srandil Desa Glempang Pasir, Kabupaten Cilacap. Penelitian ini termasuk kedalam penelitian deskriptif, yaitu penelitian yang menggambarkan fakta yang diteliti dan dimaksudkan untuk pengukuran yang cermat terhadap versi cerita rakyat tertentu. Sejauh pengamatan penulis, sampai saat ini belum ada penelitian tentang struktur, makna, dan fungsi cerita petilasan $\mathrm{Ki}$ Semar di Gunung Srandil Desa Glempang Pasir Kecamatan Adipala Kabupaten Cilacap.

\section{METODE PENELITIAN}

Penelitian ini menggunakan pendekatan deskriptif kualitatif. Data penelitian ini adalah cerita petilasan $\mathrm{Ki}$ Semar, sedangkan sumber data penelitian ini adalah tuturan dari masingmasing informan. Pengumpulan data dengan cara teknik wawancara, pengamatan secara langsung, dan teknik dokumentasi. Teknik analisi data yang digunakan dalam penelitian ini adalah teknik analisis strukturalisme LeviStrauss. Penelitian dimulai dari penentuan data yang berupa struktur cerita. Data yang berupa struktur cerita yang terdiri dari ceritemeceriteme diperoleh dengan cara membagi mitos cerita Ki Semar dari tiap informan kedalam unitunit naratif. Setiap unit naratif harus memperlihatkan relasi-relasi antar individu yang merupakan tokoh-tokoh dalam peristiwa. Penitik beratan dalam analisis ini terutama pada kalimat-kalimat yang menunjukkan tindakan 
atau peristiwa yang dialami tokoh-tokoh didalam cerita sebagai upaya untuk menemukan ceriteme. Setelah menemukan ceriteme, maka ceriteme tersebut kemudian disusun mengikuti sumbu sintagmatis dan paradigmatis untuk menemukan ceriteme-ceriteme yang mengandung relasi yang sama maupun yang tidak sama. Dengan cara ini akan ditemukan beberapa persamaan dan perbedaan antar ceriteme, sehingga akan mudah ditemukan oposisi-oposisi antara tokoh satu dengan tokoh yang lain, berdasarkan tindakan yang mereka lakukan dan peristiwa yang mereka alami.

\section{HASIL PENELITIAN DAN PEMBAHASAN}

Berdasarkan hasil analisis Struktur, Makna, dan Fungsi cerita Petilasan Ki Semar di Gunung Srandil dapat dijelaskan sebagai berikut:

\section{Struktur Mitos Cerita Petilasan Ki Semar di Gunung Srandil Terdiri dari Empat Versi Cerita}

Mitos Cerita ini dibangun dari tokoh Sabda Palon (Semar) dengan Prabu Brawijaya V. Mitos cerita tersebut dianalisis kedalam unitunit naratif kemudian digolongkan menjadi beberapa episode untuk mengetahui hubungan antar ceriteme serta oposisisi dari hasil tafsir episode. Setelah dianalisis menggunakan teori Strukturalisme Levi-Strauss maka dapat diketahui unit naratif dan episode dari setiap versi cerita. Versi cerita dari Buku Gunung Srandil dan Selok karya Sidik Purnama Negara terdiri dari 23 untit naratif yang digolongkan menjadi 3 episode, Versi cerita dari Warga Pendatang terdiri dari 9 unit naratif yang digolongkan menjadi 4 episode, Versi Cerita menurut Juru Kunci digolongkan menjadi 8 unit naratif yang digolongkan menjadi 3 episode, dan cerita versi warga sekitar digolongkan menjadi 9 unit naratif yang digolongkan menjadi 3 episode.
Mitos cerita Petilasan Ki Semar di Gunung Srandil Mempunyai Fungsi Tersendiri bagi Masyarakat Pendukungnya

Fungsi mitos cerita Petilasan Ki Semar di Gunung Srandil dianalisis menggunakan teori fungsi Van Peursen. Hasil penerapan teori fungsi Van Peursen, bahwa pada mitos cerita Petilasan Ki Semar di Gunung Srandil terdapat kekuatan ajaib. Kekuatan ajaib tersebut mempunyai hubungan yang erat dengan peristiwa atau kejadian yang dialami masyarakat pendukung mitos cerita Petilasan Ki Semar di Gunung Srandil, karena pada suatu hari ada seseorang yang telah melanggar pantangan yang diberikan oleh Sabda Palon (Semar) yaitu agar tidak menghilangkan adat jawa dan selalu melestarikannya. Mitos cerita Petilasan Ki Semar di Gunung Srandil juga memberikan jaminan hidup pada masa kini dengan melihat tingkah laku tokoh yang ada dalam cerita. Sampai saat ini tingkah laku tokoh tersebut masih ditiru oleh masyarakat dalam bentuk ritual, dengan harapan dapat memberikan jaminan pada hidup mereka.

\section{Mitos Cerita Petilasan Ki Semar di Gunung Srandil Mempunyai Makna Tersendiri bagi Masyarakat Pendukungnya \\ Makna cerita Petilasan $K i$ Semar di} Gunung Srandil dianalisis menggunakan teori Hermeneutik Hans-Georg Gadamer. Hasil analisis Hermeneutik Hans-Georg Gadamer pada mitos cerita Petilasan Ki Semar di Gunung Srandil mempunyai makna simbol yang ditafsirkan dalam cerita petilasan Ki Semar yaitu: Makna dari simbol Gunung pada masyarakat jawa yaitu tempat suci. Pada zaman dahulu, Gunung biasanya digunakan untuk mengheningkan segala tingkah laku yang berkaitan dengan duniawi. Makna Sensus Communis dalam penerapan cerita ini yaitu terdapat konsep pemikiran masyarakat tentang kehancuran majapahit yang terkenal dengan penyerbuan kerajaan Majapahit yang dilakukan oleh kerajaan Demak Bintara, padahal apabila dibandingkan dengan pendapat narasumber cerita rakyat ini, bahwa kehancuran Kerajaan Majapahit karena adanya perbedaan faham 
yang dianut oleh Raden Patah dan Prabu Brawijaya $\mathrm{V}$ sehingga membuat aturan sosial berubah di Majapahit dan mengakibatkan perang saudara. Selanjutnya adalah makna dari konsep pertimbangan, menurut Gadamer, makna ini berhubungan dengan nilai estetis, atau nilai yang mengandung keindahan. Makna dari konsep ini yaitu Gunung, merupakan tempat menopangnya banyak tumbuhtumbuhan, air, hewan liar dan pemandangan yang indah, serta mempunyai udara yang sejuk, gunung juga merupakan tempat rekreasi yang banyak dikunjungi oleh banyak orang. Taste atau Selera, cerita petilasan Ki Semar menurut warga sekitar dan pendatang mengatakan bahwa Sabda Palon (Ki Semar) merupakan penasehat Prabu Brawijaya V sedangkan cerita petilasan $K i$ Semar menurut ceita juru kunci, bahwa Semar merupakan anak dari Sang Hyang Tunggal yang diutus untuk mengasuh para kesatria berbudi luhur.

\section{SIMPULAN}

Berdasarkan Hasil analisis Struktur, Makna, dan Fungsi cerita Petilasan Ki Semar di Gunung Srandil dapat disimpulan sebagai berikut: Struktur mitos cerita Petilasan Ki Semar di Gunung Srandil terdiri dari empat versi cerita. Versi cerita dari Buku Gunung Srandil dan Selok karya Sidik Purnama Negara terdiri dari 23 untit naratif yang digolongkan menjadi 3 episode, Versi cerita dari Warga Pendatang terdiri dari 9 unit naratif yang digolongkan menjadi 4 episode, Versi Cerita menurut Juru Kunci digolongkan menjadi 8 unit naratif yang digolongkan menjadi 3 episode, dan cerita versi warga sekitar digolongkan menjadi 9 unit naratif yang digolongkan menjadi 3 episode.

Fungsi cerita Petilasan Ki Semar di Gunung Srandil dianalisis menggunakan teori fungsi Van Peursen. Hasil penerapan teori fungsi Van Peursen, bahwa pada mitos cerita Petilasan Ki Semar di Gunung Srandil terdapat kekuatan ajaib. Kekuatan ajaib tersebut mempunyai hubungan yang erat dengan peristiwa atau kejadian yang dialami masyarakat pendukung mitos cerita Petilasan Ki Semar di Gunung
Srandil, karena pada suatu hari ada seseorang yang telah melanggar pantangan yang diberikan oleh Sabda Palon (Semar) yaitu agar tidak menghilangkan adat jawa dan selalu melestarikannya. Mitos cerita Petilasan Ki Semar di Gunung Srandil juga memberikan jaminan hidup pada masa kini dengan melihat tingkah laku tokoh yang ada dalam cerita. Sampai saat ini tingkah laku tokoh tersebut masih ditiru oleh masyarakat dalam bentuk ritual, dengan harapan dapat memberikan jaminan pada hidup mereka.

Analisis Hermeneutik Hans-Georg Gadamer pada mitos cerita Petilasan Ki Semar di Gunung Srandil mempunyai makna simbol yang ditafsirkan dalam cerita petilasan $K i$ Semar yaitu: Makna dari simbol Gunung pada masyarakat jawa yaitu tempat suci. Pada zaman dahulu, Gunung biasanya digunakan untuk mengheningkan segala tingkah laku yang berkaitan dengan duniawi. Makna Sensus Communis dalam penerapan cerita ini yaitu terdapat konsep pemikiran masyarakat tentang kehancuran majapahit yang terkenal dengan penyerbuan kerajaan Majapahit yang dilakukan oleh kerajaan Demak Bintara, padahal apabila dibandingkan dengan pendapat narasumber cerita rakyat ini, bahwa kehancuran Kerajaan Majapahit karena adanya perbedaan faham yang dianut oleh Raden Patah dan Prabu Brawijaya $\mathrm{V}$ sehingga membuat aturan sosial berubah di Majapahit dan mengakibatkan perang saudara. Selanjutnya adalah makna dari konsep pertimbangan, menurut Gadamer, makna ini berhubungan dengan nilai estetis, atau nilai yang mengandung keindahan. Makna dari konsep ini yaitu Gunung, merupakan tempat menopangnya banyak tumbuhtumbuhan, air, hewan liar dan pemandangan yang indah, serta mempunyai udara yang sejuk, gunung juga merupakan tempat rekreasi yang banyak dikunjungi oleh banyak orang. Taste atau Selera, cerita petilasan Ki Semar menurut warga sekitar dan pendatang mengatakan bahwa Sabda Palon (Ki Semar) merupakan penasehat Prabu Brawijaya V sedangkan cerita petilasan $K i$ Semar menurut ceita juru kunci, bahwa Semar merupakan anak dari Sang Hyang Tunggal yang 
diutus untuk mengasuh para kesatria berbudi luhur.

\section{DAFTAR PUSTAKA}

Lutfi, Febri Ahmad. 2017. Struktur dan Fungsi Cerita Petilasan Ki Semar di Gunung Srandil Desa Glempangpasir Kecamatan Adipala Kabupaten Cilacap. Semarang: Unnes.

Ahimsa Putra, Heddy Shri. 2001. Strukturalisme Levi-Strauss: Mitos dan Karya Sastra. Yogyakarta: Galang Press. 